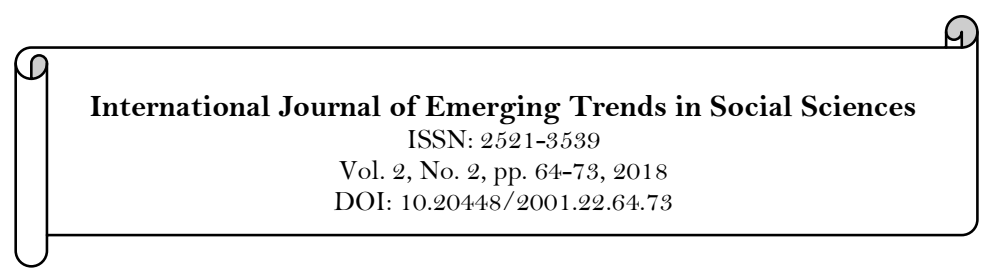

\title{
A Brief Overview on Students' Mobility and its Impact on Second language Use
}

\author{
Hadjer Chellia ${ }^{1}$ \\ ${ }^{1}$ University of the West of Scotland. \\ Email:B00281047@studentmail.uws.ac.uk
}

\begin{abstract}
This article spotlights an important facet of internationalization of higher education, namely students and research career mobility. In addition to the various attempts that some countries worldwide established to build educational bridges in order to align with the global world, the Arab world seems to have become more aware of the importance of cross-border collaborative arrangements. In this regard, this overview builds on the new developments that were globally emerged to foster mobility and exchange programmes, casting more light on the Arab world, including Algeria. The foci of the discussion around this article is to address briefly second language use among students as an important linguistic element that crossing borders could impinge on.
\end{abstract}

\author{
Keywords: \\ Internationalization \\ Mobility \\ Second language use \\ Students.
}

Licensed:

This work is licensed under a

Creative Commons Attribution

4.0 License.

\section{Publisher:}

Scientific Publishing Institute

\section{Introduction}

With the advent of globalization, the demand of a globalized world dominates even academia. One of the pillars of internationalization of $\mathrm{HE}$ is students and research career mobility, which seems to have more growing international dimensions at the current time (Organisation for Economic Co-operation and Development, 2001).

The flow of students across borders is thought to bring them into a diverse context, and therefore, a rainbow of cultures would be formed and boost their profiles. To outline the main points of this particular article, the focal point is to survey briefly issues around students' mobility and enrolment in international institutions in a wider sphere, debating its purposes, merits and constraints, and then narrowly moving to the Arab and Algerian Ph.D. research students' mobility. Issues related to second language use in the light of studying abroad programmes may also be a focus for research interests. Thereby, a spotlight is turned on to this particular section as the heart of the present inquiry.

Students' outward mobility is growing in significance. This could be demonstrated through different statistics produced by the OECD (Organisation for Economic Co-operation and Development), with a dramatic year-on-year growth. In the first instance, US, UK, Australia, Germany and France, among the OECD countries, were the top destinations for international students, with a percentage estimated at $84 \%$ of international students (Kim, 2009).

Nowadays, the contemporary world witnessed a massive global movement of international students which reached approximately 5 million in 2014, according to OECD (ICEF, 2014). However, Sussex Centre for Migration Research (2004) forecasts that the figures will rise to 7.2 million by 2020 (Coleman, 2006).

At the present time, US, UK and Australia respectively are at the core of international students market with a particular notice that the US is still ranked first (ICEF monitor, 2015). Each of these three destinations aims at recording an enormous number of international students from varied countries in the world, especially from potentially high-yield countries like China and India, using long-term strategies.

For instance, the US and Australia often provide financial incentives to target potential students (Verbeek, 2007). Likewise, in the light of the Bologna process agreement, EU countries are aiming at maintaining academic mobility with a particular goal to receive, at least, $20 \%$ of international students by 2020 (Gvetadze, 2014).

It is noteworthy, however, to draw a picture about the UK as one amongst the main recipients of international students. One of the influential factors which affect its international outlook are the two diplomatic initiatives that were introduced for the purpose of increasing international students 'mobility to 
and out of the UK; Prime Minister's initiative 1 (1999 - 2004) and Prime Minister's Initiative 2 (20062011). The former was launched to call for more non -European students while the second one was designed to further offer the UK students themselves an opportunity to study abroad (Brooks \& Waters, 2009).

Not only this but also the UK government sponsored many initiatives such as injecting $£ 5$ million to strengthen its marketing and to achieve an increased higher education market share (Binsardi \& Ekwulugo, 2003). According to OECD (2007) UK tends to send fewer students abroad, unlike the EU countries, cited in (Brooks \& Waters, 2009).

It could be due to the variety of awarding degrees institutions which have mushroomed all over the UK. One may think that this would lead to satisfaction with the quality of domestic educational provision. However, another view maintains that the number of students who want to pursue their studies outside the European Higher Education Area is growing over time and that the UK strategy for outward mobility reiterates the commitment of the UK that at least $20 \%$ of graduates from European universities will have an outward mobility for a training abroad by 2020 (Newman, 2013).

\section{International Mobility Purposes}

In the first place, a long-standing concern for student mobility lies on fortifying internationalization of HE landscape. So, one of the prerequisites of universities to be involved in this global act is to attract many students and encourage mobility. In line with this, one of the UK participants in the qualitative study of Chan and Dimmock (2008), in exploring the perception of internationalization by UK and Hong Kong universities, interestingly claimed "if you have no international students, you cannot claim to be an international university"( p.194). Accordingly, mobility aims at qualifying universities to be international ones.

In the light of the "knowledge economy" era, internationalization of HE becomes a strategy of competitiveness for many countries in the global economy, with a consideration of university ranking, and the number of the international students and scholars recruited (Kim, 2009).

Hence, the overall intent behind the internationalization of $\mathrm{HE}$ seems to be, by large, an economic one. Academic systems around the world are trying to promote students' mobility in order to foster international links, and therefore, fulfil one of the necessary imperatives of the global market (Verbeek, 2007).

At the professional level, mobility relates to career objectives in the sense of developing professional and research skills.

In the UK, Ph.D. mobility is essentially set out to promote long -term research partnerships, forming a diverse research community and exposure to new research methods and academics. In addition, it further aims at promoting intercultural skills and capitalizing on learning opportunities (Weber-Bolsey, 2010).

From the linguistic angle, students' mobility is a good strategy for the English countries to maintain their language. It also becomes a motivational drive for many universities in the globe to be international using the international language (Altbach, 2015).

One way to illustrate this point would be that among the Anglophone countries, US, UK and Australia are nowadays the engines for driving and promoting mobility exchange worldwide.

\section{Students Mobility: Merits and Constraints}

Considerable benefits and drawbacks can be derived from students' mobility, with merits outweighing its demerits, as claimed by Coleman (2006). To start with, the advantages which impel academic exchange and students' mobility in the light of internationalization of tertiary education are at the individual level and institutional level for both the native and host county.

At the individual level, immersing students in an international context is one of those merits which lead students to build up a new profile with an international perspective (Codina \& Lopez, 2013). In detail, international mobility of students stimulates the development of intercultural skills and increases learning capacities such as being creative, critical and capable of generating new ideas (Gvetadze, 2014; Weber-Bolsey, 2010).

Another key point is that overseas mobility can be seen as a discovery journey which would broaden students' horizons and makes them build professional networks.

Concerning language use experience in the new social network, the linguistic immersion and the social interaction that international students would be involved in would, to a certain extent, help them to discover a new reality.

This reality is termed as the "third space", where students are likely to gain an entry to a global community and access it through speaking the international language (Montgomery, 2010).

However, students from the same home country who are brought together within the same international context might not reach the same outcomes as mixed students do, because of the risk of remaining insular rather than interacting with others. Montgomery's study about the international students experience reports two cases that further illustrate this issue. The first case shows the difficulty of two Chinese students to speak English the whole day, despite their willingness to do so.

They chose to speak in their first language instead because it proved more practical. However another two Chinese speakers, although they are from the same homeland, had a strong desire to speak in English, 
which is also their second language, but they managed to maintain this (Montgomery, 2010). So, it might be a new avenue of research to explore the issue of international students' experience in terms of first and second language maintenance and shift in an overseas context. Montgomery's research suggests that personal determination is a key factor in speaking the foreign language (Montgomery, 2010).

For the native country, students studying abroad can bring several benefits when they come back to their home country. As a matter of fact, students who pursued their career abroad are expected to transmit the intellectual knowledge they acquired and use it to contribute to the home academic system's reforms (Arfi, 2008).

Likewise, they can gain social experiences through establishing social contacts (British Council, 2014). Through establishing social contacts with the locals, students would be culture transmitters from the host country to the native one, and vice versa. To support this idea, Tremblay (2005) argues: " a period of study abroad allows students to absorb the cultural and social customs of their host country and thus to act as an ambassador for both their host country and their own" (p.197).

The host country could more or less in receipt of some benefits. Overseas mobility could bring a high reputation to the receiving institution and enhance its economic field as well. Notably, many countries including the UK have developed HE, mainly cross-border flows to contribute to the development of their economic fields, since being involved in the global world economy and being a competitor there, may require producing a substantial number of international students (Brooks \& Waters, 2009).

International students are two-way contributors. Besides their institutional fees (tuition fees), they tend to have off-campus expenditure. Among the facets of those off-campus spending can be the different living fees, such as rent and food (In focus, 2014).

Thereby, huge incomes are produced by the international students, contributing to both the local businesses' pockets and the country's purse. Further evidence supporting the financial benefits of students' mobility may lie on the figure findings of British Council in 2014. Data gathered by this organization revealed that approximately an amount of $£ 250,000$ is daily gained from international students in the UK (British Council, 2014) whose number reached out 436,585 in 2014-2015 according to recent figures of UKCISA (2016).

Around 310,000 of those students are non -European (Gillman, 2015) largely from China and India being two top non-European sending countries, while Germany and France are the top European sending countries (UKCISA, 2016). Thereby, they add contributions to the British economy (British Council,2014). The number of international students is projected to rise markedly in the future (UKCISA, 2016).

With a particular reference to Chinese students, recent figures produced by UKCISA (2016) have shown that Chinese students represent the highest proportion of international students in the UK with a number exceeds the one of other students from other nationalities with 89,540 in 2014-2015 (UKCISA, 2016). As a consequence, they yield giant financial contributions to the British universities.

Be that as it may, students' mobility programmes have a host of hurdles. Among the common limitations of these programmes in the world is the fact that students' mobility towards an international institution might become a brain drain, especially in the Arab World (Abu-Orabi, 2013).

The case of Algerian students who were awarded scholarships to the US and France in the late 1970's and early 1980's with the intention of acquiring knowledge in the developed North and West, is an epitome in this context. Some of these students did not come back to build the Algerian young nation state (Arfi, 2008). India, in the same way, encountered this issue of brain drain. Many Indian students graduated from US academic institutions refused to go back. As a reaction to this, India is trying to be an important participant in internationalization of HE landscape (Altbach, 2015).

Although brain drain can be a loss from the native countries' perspective, the receiving countries of students often support this phenomenon, and therefore, becomes a brain -gain for them. In this regard, some OECD countries do not only support students' flows but also permit highly skilled to apply for residence status (Tremblay, 2005). However, this perspective has been changed starting from 2012, in which the British government has introduced strict visa regulations. The visa immigration policies aimed at slashing the chances of employing international students in the UK after graduation. The new visa rules brought down the rate of overseas students who have particular potentials to secure a future job with a percentage roughly estimated at $88 \%$ (Petroff, 2015).

In the same fashion, cross-border flows for higher education can lead students to lose their cultural identity (Coleman, 2006). By the same token, Montgomery (2010) argues "It is interesting to note that upon coming to a new educational context, international students are continually forced to restate and renegotiate their identity" (p.100). Along similar lines, international students, during their educational journey can be involved in the so-called "third space", in which they supposedly face an identity dilemma. Another important constraint which might influence internationalization of HE in general and overseas students in particular is the use of English as the main language of instruction which is triggered by globalisation. This later stimulates the idea of monolingualism, while it should support multilingualism and multiculturalism (Chan \& Dimmock, 2008). On the whole, some impediments that might be encountered by students can be, at the long run, recognised as benefits. For example, the differences in methods and approaches can be among the 
constraints that students face during their course abroad; however it may prove beneficial in return (OECD, 2001).

\section{Student Mobility in the Arab World}

In the Arab World, more intra-Arabs programmes were founded by the Arab Council in order to impel mobility exchange between Arab universities. The main intent is to preserve the Arab culture and civilization (Abu-Orabi, 2013).

To internationalize HE, academic initiatives have been undertaken by the Arab states in pursuing the knowledge economy, through adopting different models of HE policies. However, more light is casted on the so-called imported internationalization, which consists of inviting international institutional bodies to set up their campuses on the Arab World, mainly in the Gulf States. These institutions are given prestigious brands to attract international students such as North-western University in Qatar (Buckner, 2011). Indeed; some countries of Asia and Middle East have a driving ambition to become an annex to the international education centres, in order to attract many international students (Verbeek, 2007).

To build more cultural bridges, The Arab World launched many academic programmes emphasizing student mobility.

Among the recently drawn up ones is the Programme for Excellence Academic Cooperation Exchange (Peace) (2012-2016) and Development of a Higher Education and Research Area between Europe and the Middle East HERMES" (2013-2017), whose main aims are to integrate Middle East Universities within the European HE, to harmonise the curricula and diplomas in accordance to the Bologna process, and to foster undergraduate and post graduate students 'mobility (Abu-Orabi, 2013).

European Universities 'target to draw more international students includes the Arab world. Nevertheless, France seems to be the first destination to attract Arab students from both Anglophone and Francophone countries with a percentage estimated at $28 \%$, followed by US (13\%), according to UNESCO figures (2012), although, economically speaking, there was more heavy marketing by the UK and Australia (Elmeshad, 2014). It might not be only linked to the historical ties but it, to some extent, evidences France's growing willingness to maintain a global reach.

Numerous attempts were made to encourage Ph.D. s mobility from the Arab world to the UK. Notably, the Go Study UK website (2009) lists some scholarships programmes that are offered by Great Britain. It would be; however, more constructive to speak about the Arab-British Chamber of Commerce which is a significant student grant programme.

This programme is an ample opportunity for Arab students pursuing postgraduate research, since it offers a partial grant reaches up to $£ 2,000$ (Go Study UK, 2009). Similarly, it is worth considering the Weidenfeld Scholarships and Leaderships Programme which aims at building future ties with different parts of the world including the Middle East and North Africa. Under this programme, postgraduate research students in Oxford University would be benefited from a fully funded scholarship including the payments of all the fees (Go Study UK, 2009).

\section{Mobility: From the Arab World to Algeria}

In Algeria, different bottom -up activities to encourage mobility programmes have been undertaken. In what we are discussing herein, the main concern is to shed light on the Algerian doctoral mobility which contributes to the internationalisation of $\mathrm{HE}$.

In the first place, owing to the French imperialism in Algeria and the economic ties that both countries have had, there was a high level of cooperation between both lands. With the adoption of the Bologna process model, the French launched some programmes that offer financial support to the Algerian students. One way of exemplification is the Franco-Algerian scholarship programme (2009), which was an opportunity for Algerian students.

In this programme, only $40 \%$ of the fees is required from the Algerian government, while $60 \%$ would be covered by the French one. In 2009, around 300 Algerian Ph.D. students have enrolled in French institutions under this programme (Geschwind, Hellman, \& Mattsson, 2010). More than that, in the context of Higher education and scientific research, the Algerian president; Abdelaziz Bouteflika and the French one; Francois Hollande signed an agreement in 2012 to foster the Algerian students' mobility to France including Ph.D. students (Zouaghi, 2015).

With the diffusion of English language in Algeria, some English graduate programmes were introduced. However, it seems that it is only recently that English doctoral programmes started to be considered. The case of US could be a constructive example.

The US embassy in Algeria provided a variety of programmes for Algerian citizens such as the Fulbright and Youth Leadership Programmes (Belmihoub, 2012). Both of them, nonetheless, were limited to graduate studies. By all means, it could be the platform upon which doctoral programmes will stand on in the distant future. 
In a more narrowed scope, an ambitious plan was recently drawn up by Algeria to enter into international partnerships with the Anglophone world. The UK government and the Algerian Ministry of Higher Education worked towards an agreement to send up to 500 Ph.D. students, who are in receipt of a fully funded scholarship to pursue a career leading to a doctor of philosophy, to the UK in the period of 5 years (The British Council, 2014). The long-term objectives of this academic exchange are to build cultural bridges between both countries and to internationalise the Algerian HE system (The British Council, 2014).

\section{Study abroad and Second language Use}

International students around the globe could experience effects on their language use as they encounter diverse nationals and home students with different linguistic backgrounds. Research studies have put forward some narratives of students' experiences in residing abroad. Each may narrate a different experience of language use but ultimately reaching what can help develop this section. In this passage, second language use is restricted at this point to the target language rather than the pre-nominated second language of émigré students as such.

For example, in the case of Algerian students in the UK, the focus at this stage would be on their use of English (target language) as opposed to studies looking at the effect on their second language (French). There is, simply, very little research other than on this issue of target language. One reason for this could be that when students cross borders to develop their careers, the main concern is to develop their second language, like the case of Chinese students in Anglophone countries. In this case, research focuses on their proficiency or not in English. It is not a purpose of student mobility to develop a second language and so the research rarely considers this issue.

For example, in a UK case, English-speaking students from Wales who went to France as part of their degrees, would be expected to develop skill in French and whether or not there was any impact on their proficiency in Welsh (their second language) while residents in France, is unlikely to have been studied. One hypothesis is that such students, however, may tend to adopt subtractive bilingualism which entails a lessening of their pre-migratory second language and substituting it with the target language. In this section, the discussion centres on language experience amongst students abroad with a particular focus on second language identity and use, where such limited research is available. So, it goes without saying that second language abroad varies from one émigré community to another .It could be an incentive for them to develop their second language, a risk factor to losing any language as it can be a chance to gain another foreign language.

With the advent of internationalisation of higher education and university exchange programmes, educators and programme designers have subscribed to the view that being abroad is a great opportunity to use the target language, expanding students' horizons and building social networks with native speakers and other international students (Dewey \& Hillstrom, 2013).

A point to strengthen this view is what is stated by Aveni and Pellegrino (2005) "teachers and students have long believed in the powers of study abroad for second language education, the extensive authentic interaction with native speakers that in country -living can provide cannot be duplicated in the classroom “(p.1). With regard to L1 use, reducing its use seems also a long-term objective of the exchange programmes. Benson, Barkhuizen, and Bodycott (2013) speculates "one expectation of a longer-term and deeper immersion in a second language environment might be a stronger affiliation with the second language culture and a corresponding weakening of attachments to the first language culture"(p. 110).

Benson's research would suggest that the situation would be even worse for L2. For example, if a French student finds that his French capacity diminishes when in an Anglophone setting, one would expect that this would be even more marked if he had a second language. In the example cited above, one would think that the students from Wales would find English use being impacted by residence in France, but that this impact could be even greater on their second language - Welsh.

It could be argued that among the purposes of university exchange programmes is to foster linguistic immersion. The Algerian mobility programmes in the UK, in this particular respect, may aim at developing students' English language use.

One effect of this could be reducing L1 and prior L2 use so that English gains strength and their use of Arabic or Berber or French could diminish. So, study abroad can be proved an important context to develop second language use through the immersion and contextualisation processes especially for those who travel to the native country of their actual second language in their homelands. In the case of Algeria, this would most commonly refer to France, for example. It can be an affordance for the spontaneous use of a target language.

Aveni and Pellegrino (2005) investigated second language use among American students abroad. Data were collected through analysing long narrative journal diaries, questionnaires and ethnographic interviews. Aveni and Pellegrino studied the language use experience of 76 American students residing in Russia for the purpose of Russian language learning.

Their study is designed to meet two aims: exploring the barriers that hamper second language use among American students in Russia and identifying the communicative use of second language rather than its acquisitive use. Focusing on self-presentation and self- preservation, the researchers reported on an important 
hindrance. This has to do with the risk of being misperceived which would affect the self-image when communicating ideas. Thus L2 learners may find themselves uncomfortable in interacting with local people and may fear that their audience perceive them as lacking sociolinguistic competence (Aveni \& Pellegrino, 2005). Therefore, learners in studying abroad may fall in a dilemma concerning their second language use. This reluctance impedes their capacity to develop the target language.

What is really prominent in this sociolinguistic study, nonetheless, is that the researcher nominated Russian as a second language for American students in Russia. This would build another assumption that Algerian students -when study in the UK -adopt English as a second language. However, as has been noted throughout this study, the Algerian language context is much more complex and one cannot make such simple assumptions about the "second language".

\section{Study in an Anglophone country and L2 Use}

Crossing borders towards Anglophone countries can be presumably seen as the best context for promoting English language use. Benson et al. (2013) developed an understanding of second language identity and study reconceptualising the processes and outcomes of second language learning. In their inquiry, by focusing on identity -how we represent ourselves to ourselves -, the chief aim is to look how learning a second language abroad affects the learner as a person over time.

Essentially, this study illustrates well the point that learning abroad can be starting point for second language identity development. This concept refers to how we view ourselves as speakers of that language and our relationship to that language. Norton and McKinney (2011) argue that "every time learners speak, they are negotiating and renegotiating a sense of self in relation to the larger social world, and reorganizing that relationship in multiple dimensions of their lives"(p.73). In this view, identity is a central issue of language learning.

Benson et al. (2013) carried out a narrative investigation of 48 Hong Kong students in a duration of three -year in different recipient locations such as Canada, Australia, New Zealand, Germany, Norway, Korea, the United Kingdom and the United States. The aim of students 'courses in the already mentioned destinations is not only to develop their English but also to study through English as medium of instruction. To gain a deep understanding of students 'second language identity and experience, the researchers went through the narratives of individual case studies.

Those participants belong to different profiles, ranging from secondary school to post graduate degrees students. The researchers studied the narratives of each student's experience of second language abroad through interviews and written accounts. Before their departure, the participants were interviewed on their expectations about studying abroad. Interviews were both designed in English, their second language, and their mother tongue Cantonese. One reason for this could be to take into accounts that interviewees still have less communicative in their L2.

According to their prior experiences, they had different perspectives and backgrounds. One student of the one-semester exchange programme tended to have a positive impression and high expectations of her short tour in the United Kingdom. 'Angelina' expected an exposure to spoken and written English in a more professional and academic way. Embarking on her courses, the student reports that studying abroad did develop her second language identity and made her stronger in the sense that being isolated in a "wild world" as referred to by her, naturally made her stronger to survive in a foreign setting and developed her L2 use (Benson et al., 2013).

One can assume that those who keep less contacts with people whom they left behind them, achieve more second language outcomes and develop its use. At the other end of the spectrum, those who keep in touch with their homeland fellows would face some linguistic crises. This point is greatly sustained by Dewey, Belnap and Hillstrom who put "In several studies learners who maintained strong ties with family and friends at home while abroad through email and telephone failed to create strong social networks and suffered linguistically" (2013,p.86).

However, it gives the feelings that maintaining a close tie with nationals from the same homeland would provide a safe and a secure linguistic environment. Montgomery 's study regarding the nature of international students and home students 'friendship in studying abroad can be appropriate to illustrating this important point by reporting some responses gained from interviewing different international students. One common perspective shared by his sample member is that it is of a prime importance to keep social ties with some friends from the same nationality. They reported that they have at least one to two friends from their own nationality which provides them with an emotional setting, albeit their strong tendency to develop international friendship and establish ties with home student (Montgomery, 2010).

It could be maintained that being associated with people with the same national identity would contribute to constructing a strong emotional environment among the émigrés 'students in the diaspora, while being isolated would foster developing intercultural communication and promote more second language use. However, both views, as shown in both studies, could be described as complementary to provide a secure linguistic environment and this is best put by Benson et al. (2013). 
Through drawing on two of their interviewees 'experiences of target language use, they document the participants 'strong motivation to preserve Hong Kong cultural identity and engaging with English cultural context. This presents something of a paradox: being isolated abroad may seem to be better for language acquisition but it may come at the cost of emotional stability that would enhance language acquisition; remaining close to one's linguistic peers may be good for well-being but may reduce one's development in L2. It is worth focusing on students who were pursuing a post graduate degree career in Benson et al. (2013) study, probing postgraduates' experience of the target language use in studying abroad. Attitudes were both negative and positive.

According to Daisy's narrative, one of the postgraduate participants, her socio-pragmatic competence and motivation were developed in Hong Kong before pursuing a Bachelor's in the Netherlands and a Master's degree in applied linguistics in the United Kingdom. Some passages from interviewing her indicate her experience of English language use. Above all, Daisy developed successful reading habits both in Chinese: as a first language and English: as a second language before undertaking migration. Her perspective towards English was positive from the beginning. Her narrative illustrates that she used to produce written compositions both in English and Chinese in her secondary school as she acknowledges:

Briefly speaking, one difference could be I tend to give more real-life examples and

evidence in English, while I tend to make full use of the vocabulary I know in

Chinese to express abstract meaning and ideas (cited in Benson et al. (2013)).

The sentiments expressed in this quotation embody the view that one reason of using English when giving real life examples would be that she had been aw are of the global value of English before her journey of studying abroad started. This, in addition to her choice for English degree in university would make one's mind to expect that the participant will experience high English language use and second language development with the immersion.

However, Daisy's perspective towards English has altered as she graduated from Netherlands university: from considering English as a tool of expressing ideas to viewing it as an art. It developed from mere functional competence. Enrolling in a Master degree in applied linguistics in London, Daisy set up some predeparture goals concerning language development. Among those aims were language gains, improving her accent, building social contacts with local students, and establishing friendship groups. Despite her willingness to develop her second language use ,she also desired to preserve her first language :Chinese through writing in web-blogs and joining facebook groups where she maintained contacts with her friends in Hong Kong .Concerning Cantonese, Daisy had little exposure to speaking it ,but rather had a successful trial of promoting Mandarin Chinese use which really surprised her.

In this respect she claims "I expected only to improve my English but I didn't expect that my Mandarin would improve a lot"(p.98) cited in Benson et al. (2013). According to Daisy 's experience, studying abroad ,the academic context she was exposed to and working as part-time interpreter in one of the hospitals did not only influence her second language use but also built an intrinsic motivation to develop her first language so as she can benefit other students in learning Mandarin. Overall, Daisy‘s expectations concerning developing second language use were met.

Concerning language gains, she was exposed to a deep immersion during her daily activities like shopping and joining trips made her learn some slang expressions. The participant's attitude towards cultures has been changed and she developed awareness of cultural differences and therefore developing intercultural competence. In this sense, she maintains "I have got into contact with many different people with different histories and now I know that there are reasons behind every action that a person does "(cited in Benson et al. (2013)).

It is very illuminating to draw on Daisy's experience of language use as postgraduate student in the UK .One conclusion can be drawn from this key study is that study abroad is a significant context for promoting second language use and developing its identity. Benson et al best summarises Daisy's experience when they say" "She found that she was able to engage with strangers effectively and systematically in English and , as a result ,her second language identity and personal competencies developed hand in hand "(Benson et al., 2013) Nevertheless, this study, as involving only Hong Kong students whose pre-migratory second language is already English could be hard to generalise its results about other students in which English is nominated as a foreign language in their homelands.

However, this study could be very applicable to postgraduate students in the UK as they have similar aims in which developing the target language use is a crucial matter. Algerian postgraduate students in the same context, in addition to their professional aim that is obtaining a career degree, developing English may also a concern for them as well. The problem of this issue lies on French use whose fate in the UK among Algerian students is still worth researching. The main question is that, if Algerian students go through the same experience of Daizy, are they going to use English as a second language in their speech, or maintain French and develop English use simultaneously. These questions simply lead to one assumption which is "they may face second language identity crisis": maintaining the pre-migratory second language or subtracting its use with more English. 
Likewise, Sato (2014) in analysing the narratives of three Japanese students, sought to find out the impact of short-term study abroad on second language identity construction. The main point deduced from his study is that social interaction with daily encounters can affect second language identity construction. In interviewing one of the participants, there might be some reinforcements.

The informant "Akiko " during her study in New Zealand regarding communicating through the actual use of English elucidates her willingness to use English instead of Japanese. Unlike in Japan in which speaking in the second language can be associated with the fear of considered as a "showing off", being in New Zealand made her strengthen her initiative to speak the target language and, therefore, preferably construct her second language identity: from someone of less confidence to someone with a full desire and confidence (Sato, 2014).

Further evidence supporting this work can be the study of Gao (2008). His research work outlines the relationship between Chinese learners identities and their second language during their learning journey in the UK, how their identities affect their second language and how these identities are reconstructed in an English context.

Gao himself draws on his own experience as a postgraduate MA student in York university as he experienced a change in his identity, and this is his main rationale in embarking on a PhD research. The findings of his inquiry came to an important conclusion - that is, acquiring a deep understanding of students 'study abroad journey may necessitate probing into their identity reconstruction and transformation, an important aspect which should be taken into account in the present work. By the same token, issues related to gender are also addressed in Gao's study which is, to a certain extent among the initial concerns of this work. His focus is to seek the relationship between gender identity and second language development. Observing six participants 'utterances of his sample, he noticed the potential impact of the parents' gender on the participants 'gendered self-images and how this influences their learning outcomes.

Gao initially demonstrated how a female gender mother can increase learning interests on her daughter and how a male gender father can do on his son. On the whole, what generally emerges from interviewing the six participants is that they adopted some of their parents 'character. To illustrate, Zhu and Xu decision; two the male Chinese students in England, are more influenced by their fathers 'decisions and they tend more to follow their opinions. In this sense, Zhu acknowledges" We will respect all of his opinions, although some opinions are wrong "(quoted in Gao (2008)) and the later declares "My father wanted me to study abroad long ago "as quoted in Gao (2008). It is not clear if these gender issues are specific to the Chinese context reported here, or if there is any wider evidence of its impact.

As concerns accessing learning opportunities abroad, the social engagement seems also to be associated with students' gender. In this respect, Gao expresses "It seems that there is a gender difference between female Chinese learners and male Chinese learners 'access to linguistic resources in Britain"(pp.146-147). In an interview with one of the six participants "Jin”; an English course Chinese student being a student in Britain for more than one time, the utterances demonstrate that gender plays a big role in the way students abroad interact; female students encounter more difficulties, more emotional and tend to be less helpful, while boys have access to more interaction opportunities, more keen on establishing friendship ties and tend to have a quick ability to learn English (Gao, 2008).

What is more, female students tend more to promote reading and writing skills more swiftly than boys who are more inclined towards developing their listening and speaking, a two skills that girls less focus on .Jin clearly declared to support these given points " Girls prefer stable lives, and they spend every day peacefully. Girls have fewer chances to speak. You can see this from the frequency that girls speak in the class. Girls' academic English should improve very quickly, but their speaking and listening are not as good as boys", a verbatim passage from Jin's declaration as quoted in Gao (2008).

The focus of this section is somehow less relevant to the present work as it sheds more light on the relationship between gender, identity and second language learning. It could ,however, lend support to this piece of research since gender could be an important determinant in second language use among Algerian $\mathrm{PhD}$ students in the UK, and therefore, worth considering.

To explain more, Algerian mothers who use French with higher rates in Algeria, as an instance, can have a great role in fostering French language retention among their daughter students pursuing a career in the UK when getting in familial contacts. Algerian fathers similarly can do. What is more, the ratio of French use among émigrés PhD students in the UK can be gender-dependent per se.

It is, thereby, foreseen that French use would be more retained among Algerian female students than male ones as they, following what Gao (2008) assumes, seem to be more influenced by their mothers, apparently tend to show more French prestigious usage in Algeria. However, educated people with highly intellectual profiles, be it males or females, tend to valorise French use in their speech .French use might be preserved among Algerian intellectuals in the diaspora if their former verbal repertoires are transferable to the abroad context.

Approximately all the aforesaid studies seem to be restricted only to the "during "period of studying abroad, with less regards to the "pre" and "post" ones, with the exception of Benson et al. (2013) who conducted an interview with participants in their pre-arrival to know their aspirations and expectations. So, language use and choice abroad seem to depend on the person you are talking to, the context and the issue 
discussed itself. In this regard, students in an abroad English context tend to use English with native speakers, while their L1 with students from the same sociolinguistic backgrounds. Campbell's study on Japanese students language use experience abroad can be used as a way to evidence this.

To gain a deep understanding of students' social networks and language use in studying abroad and the main factors that affect them. Campbell (2015) went through a thorough analysis of six Japanese interaction journal and interviews. In probing patterns of language use and the main factors influencing this use, the findings generally describe those patterns as complex and tend to differ from one informant to another, from one situation to another, from one particular topic to another.

To illustrate this compelling point; one of the informants Alex declares that he uses Chinese and Korean when interacting with those from the countries of the respective nationalities. Sophie, another participant prefers to use Japanese when talking about the Japanese culture, traditions and customs, and tends to insert some Japanese words while taking to the other English speaking friends. Marie, on the other hand, acknowledged that she sometimes use French words with her British friends like when talking about the French wine (Campbell, 2015).

One can reflect on the aforementioned participants' experiences on second language use abroad. The commonality between these studies entails that second language use is variable and apparently differs from one individual to another. Thereby, sociolinguistic studies about language use in the diaspora may require going through a narrative method of analysis for each participant journey so as to gain an in-depth data and to reflect on their experiences thoroughly.

On the basis of the evidence currently available, the foregoing discussion implies that students' and research career mobility could be a giant leap towards a more global openness and an important indicator of a developing field in the HE sector, owing to the beneficial outcomes they can have. With regards to the social and linguistic experience, study abroad in a diverse community and intercultural encounters is an important activity which could rebuild students' intercultural, academic and socio-pragmatic competences. Nevertheless, it can be a positive experience as it can be a negative one, depending on meeting one's expectation.

\section{References}

Abu-Orabi, S. T. (2013). Higher education and scientific research in the Arab world. Retrieved from http://www.ub.edu/mwginternal/de5fs23hu73ds/progress?id=3P3KGTUdcbWpG55V_XdCCrZBcZjDnpYev Bo2FZO9Wdo.

Altbach, P. (2015). Perspectives on internationalizing higher education. International Higher Education, 27, 6-8.

Arfi, K. (2008). Languages of Algerian diaspora in the United States of America: Comparative study with Algerian diaspora in France: University of Florida.

Aveni, V. P. A., \& Pellegrino, V. (2005). Study abroad and second language use: Constructing the self. Cambridge: Cambridge University Press.

Belmihoub, K. (2012). A framework for the study of the spread of English in Algeria: A peaceful transition to a better linguistic environment.

Benson, P., Barkhuizen, G., \& Bodycott, P. (2013). Second language identity in narratives of study abroad. United Kingdom: Palgrave Macmillan.

Binsardi, A., \& Ekwulugo, F. (2003). International marketing of British education: Research on the students' perception and the UK market penetration. Marketing Intelligence \& Planning, 21(5), 318-327. Available at: $10.1108 / 02634500310490265$.

British Council. (2014). The start of a training session in English for the benefit of 14 teachers in preparation for the reopening of the British Council next September Dzaers. Retrieved from http://www.djazairess.com/ennahar/201097.

Brooks, R., \& Waters, J. (2009). International higher education and the mobility of UK students. Journal of Research in International Education, 8(2), 191-209.

Buckner, E. (2011). The role of higher education in the Arab State and society. Journal of Comparative \& International Higher Education, 3(Spring), 21-26.

Campbell, R. (2015). Life post-study abroad for the Japanese language learner: Social networks, interaction and language usage. Social Interaction, Identity and Language Learning During Residence Abroad, 241-262.

Chan, W. W. Y., \& Dimmock, C. (2008). The internationalization of universities: Globalist, internationalist and translocalist models. Journal of Research in International Education, 7(2), 184-204.

Codina, J. N. B., \& Lopez, R. H. L. (2013). The importance of Student mobility, academic exchange and internationalization of higher education for college students in a globalized world: The Mexican and Latin American case. Retrieved from http://philpapers.org/rec/BARTIO-24.

Coleman, J. A. (2006). English-medium teaching in European higher education. Language Teaching, 39(01), 1-14. Available at: http://dx.doi.org/10.1017/So26144480600320X.

Dewey, B., \& Hillstrom, D. P. R. K. (2013). Social network development, language use, and language acquisition during study abroad: Arabic language learners' perspectives. Frontiers: The Interdisciplinary Journal of Study Abroad.

Elmeshad, M. (2014). Top European destination for Arab students. Retrieved from http://www.alfanarmedia.org/2014/01/france-and-germany-top-european-destinations-for-arab-students/.

Gao, F. (2008). The investigation of Chinese learners' identities and their English language learning journeys in Britain. $\mathrm{PhD}$ Thesis, University of Kent.

Geschwind, G., Hellman, H., \& Mattsson, L. (2010). Study on the organisation of doctoral programmes in EU neighbouring countries Algeria www.technopolis -Education and Culture DG. 
Gillman, O. (2015). More Chinese students in the UK than from the whole of the EU. Daily Mail. Retrieved from http://www.dailymail.co.uk/news/article-2913109/Huge-influx-Chinese-students-UK-universities-arriveEU.html.

Go Study UK. (2009). Information on UK postgraduate scholarships specifically for Middle Eastern students. Retrieved from http://www.gostudyuk.com/study.jsp?id=STUDY_MIDEAST_FUNDING_POSTGRADUATE_SCHOLARS HIPS.

Gvetadze, S. (2014). Financing the mobility of students in European higher education. European Investment Fund January, $2-41$.

ICEF. (2014). Summing up international student mobility in 2014. Retrieved from http://monitor.icef.com/2014/02/summing-up-international-student-mobility-in-2014/.

Kim, T. (2009). Transnational academic mobility, internationalization and interculturality in higher education. Intercultural Education, 20(5), 395-405.

Montgomery, C. (2010). Preparing for life in a global community? Understanding the international student experience. Houndmills, Basingstoke, Hampshire: Palgrave Macmillan.

Newman, J. (2013). UK strategy for outward mobility. UK Higher Education International Unit.

Norton, B., \& McKinney, C. (2011). An identity approach to second language acquisition. Alternative Approaches to Second Language Acquisition.

Organisation for Economic Co-operation and Development. (2001). Innovative people: Mobility of skilled personnel in national innovation systems. Paris: OECD.

Petroff, A. (2015). Foreign students ditch dream of work in the UK. CNN. Retrieved from http://money.cnn.com/2015/09/08/pf/college/uk-international-students-visa-work.

Sato, T. (2014). The effects of study abroad on second language identities and language learning. Turkish Online Journal of Qualitative Inquiry, 5(3), 28-41. Available at: 10.17569/tojqi.56715.

Tremblay, K. (2005). Academic mobility and immigration. Journal of Studies in International Education, 9(3), 196-228. Available at: $10.1177 / 1028315305277618$.

UKCISA. (2016). International students in UK HE - international student statistics: UK higher education. Retrieved from http://institutions.ukcisa.org.uk/Info-for-universities-colleges--schools/Policy-research--statistics/Research-statistics/International-students-in-UK-HE/\#International-(non-UK)-students-in-UK-HE-in-2014-15.

Verbeek, L. L. (2007). International student mobility: Patterns and trends. The Observatory on Borderless Higher Education.

Weber-Bolsey, G. (2010). Beyond immersion. In E. Jones (Ed.), Internationalisation and the student's voice: Higher education perspectives (pp. 55-67). New York: Routledge.

Zouaghi, A. (2015). For mixed experience between Algeria and France. Retrieved from http://www.ultrasawt.com. 